EESTI NSV TEADUSTE AKADEEMIA TOIMETISÉD, 22. KOIDE KEEMIA * GEOLOOGIA. 1973, NR. 1

ИЗВЕСТИЯ АКАДЕМИИ НАУК ЭСТОНСКОП ССР. ТОМ 22 ХИМИЯ - ГЕОЛОГИЯ. 1973, 수 1

удК $665.6 .032 .57-404.9: 543.42$

\author{
Ю. ЛИЛЛЕ, Т. ПЕХК, Т. ПУРРЕ, Л. БНТТЕР
}

\title{
ИССЛЕДОВАНИЕ СТРУКТУРЫ ТЯЖЕЛОЙ СЛАНЦЕВОИ СМОЛЫ МЕТОДОМ ЯМР-СПЕКТРОСКОПИИ
}

По данным дегидрнрования с серой около $60 \%$ углерода и $40 \%$ водорода керогена сланца-кукерсита находится в гидроароматических циклах [1] и поэтому в тяжелой смоле можно предположить в основном циклическую структуру. Результаты исследования состава продуктов восстановления термобитума [ $\left.{ }^{2}\right]$, гидрирования асфальтенов [3] и силикагеле вых смол [ $\left.{ }^{4}\right]$, окисления тяжелой смолы [5] и выделения ряда индивидуальных соединений $\left[{ }^{6}\right]$ подтверждают это предположение. Однако в этих работах распределение углерода определялось косвенно по составу продуктов деструкции, используя ряд дополнительных допущений. Количество выделенных индивидуальных соединений составляет лишь небольшую долю от тяжелой смолы.

${ }^{1} \mathrm{H}$ - и ${ }^{13} \mathrm{C}$-спектры магнитного резонанса позволяют непосредственно определить распределение водорода и углерода между структурными элементами молекул (хотя в смесях нельзя определить всех деталей) и поэтому ЯМР-спектроскопия имеет бесспорные преимущества перед любыми деструктивными методами.

Целью данной работы является характеристика всей тяжелой части сланцевой смолы полукоксования методом ЯМР-спектроскопии. Причем использовалась также ИК- и УФ-спектрофотометрия. Полученные резуль. таты показали, что около $60 \%$ углерода тяжелой смолы находится в насыщенных неразветвленных цепях. Характерной структурой среди двухатомных фенолов является структура 5-алкилрезорцинов.

\section{Экспериментальная часть}

Были исследованы следующие пробы (табл. 1):

I и II пробы составляли соответственно двух- и одноатомные фенолы, выделенные из суммарных фенолов тяжелой смолы туннельных печей сланцехимического комбината «Кивиыли» путем хроматографирования на тонком слое окиси алюминия, содержащей $2,5 \%$ воды. Толщина слоя 2 мм, размеры пластины $200 \times 240$ мм, величина пробы 500 мг, растворитель - бутилацетат-дихлорэтан (4:1). Проба I отбиралась от старта до 2-метилрезорцина, проба II - выше 2-метилрезорцина. Фракция на фронте растворителя (около 4\%) далее не анализировалась. Потери составляли около $25 \%$. III проба - промышленный остаток атмосферной дистилляции генераторной смолы. IV, V и VI - соответственно углеводороды, нейтральные кислородные соединения и фенолы, полученные из пробы III путем обработки ее одновременно петролейным эфиром и сме-

2 ENSV TA Toimetised $\mathrm{K} * \mathrm{G}-11973$ 
Характеристика проб

Tаблища 1

\begin{tabular}{|c|c|c|c|c|c|c|c|}
\hline \multirow{2}{*}{ Проба } & \multirow{2}{*}{ M } & \multirow{2}{*}{ C, $\%$} & \multirow{2}{*}{$\mathrm{H}, \%$} & \multirow{2}{*}{$\begin{array}{c}\text { O, \% } \\
\text { по раз- } \\
\text { нице }\end{array}$} & \multicolumn{2}{|c|}{ ОН/моль } & \multirow{2}{*}{$\begin{array}{c}\text { Выход } \\
\text { от сум- } \\
\text { марной } \\
\text { смолы, } \\
\%\end{array}$} \\
\hline & & & & & $1^{*}$ & $2^{* *}$ & \\
\hline $\begin{array}{r}\text { I } \\
\text { II } \\
\text { III } \\
\text { IV } \\
\text { V } \\
\text { VI } \\
\text { VII }\end{array}$ & $\begin{array}{l}368 \\
356 \\
412 \\
355 \\
426 \\
298 \\
308\end{array}$ & $\begin{array}{l}78,37 \\
79,62 \\
83,42 \\
85,99 \\
82,61 \\
79,60 \\
84,24\end{array}$ & $\begin{array}{l}8,58 \\
7,85 \\
8,38 \\
9,58 \\
9,10 \\
8,32 \\
9,25\end{array}$ & $\begin{array}{r}13,05 \\
12,53 \\
8,20 \\
4,43 \\
8,29 \\
12,08 \\
6,51\end{array}$ & $\begin{array}{l}2,0 \\
1,4 \\
0,9 \\
0,5 \\
1,1 \\
1,4 \\
0,7\end{array}$ & $\begin{array}{l}1,7 \\
1,4 \\
1,1 \\
1,4 \\
1,7 \\
0,5\end{array}$ & $\begin{array}{r}7,0 \\
6,2 \\
60,0 \\
26,4 \\
25,7 \\
7,9 \\
100,0\end{array}$ \\
\hline
\end{tabular}

* По Михкельсону.

** По балансу этерифицирования.

сью метанола с ацетоном по [7]. VII проба - суммарная смола 5-газогенераторной станции.

Bсе пробы, кроме I и II, отобраны на сланцеперерабатывающем комбинате им. В. И. Ленина в г. Кохтла-Ярве.

Молекулярные веса и содержание гидроксильных групп определялись по Михкельсону [ ${ }^{8,9}$. Триметилсилирование проб проводилось действием гексаметилдисилазана по общеизвестной методике.

Протонные спектры снимались на универсальном спектрометре ЯМР [10] при комнатной температуре на частоте 40 мәц в виде $30-$ $50 \%$-ных растворов в четыреххлористом углероде.*

Для раздельного определения сигналов протонов гидроксильных групп и ароматических ядер, наблюдаемых в области $6-8$ м. д., спектры снимались, во-первых, в диметилсульфоксиде [1'], где сигнал кислого протона перемещался до 9,3 м. д., и, во-вторых, после триметилсилирования гидроксильных групп. В последнем случае замеряли сигнал девяти протонов соответствующих метильных групп в эфире фенола $\left(\mathrm{CH}_{3}\right)_{3} \mathrm{SiOPh}$ около 0,25 м.д. Более выгодным оказался последний способ, поскольку он позволяет контролировать также содержание спиртовых гидроксильных групп (сигнал от $\left(\mathrm{CH}_{3}\right)_{3} \mathrm{SiOAlK}$ наблюдается у 0,06 м. д. $\left.\left[{ }^{12}\right]\right)$. Однако для этого следует провести этерифицирование гидроксильных групп со свежеперегнанным реагентом во избежание содержания продуктов гидролиза последнего.

Условия снятия ${ }^{13} \mathrm{C}$ и ИК-спектров описаны ранее $\left[{ }^{13,14}\right]$. При расшифровке ЯМР-спектров были использованы $\left[{ }^{15}, 16\right]$.

По данным распределения атомов водорода и углерода попытались определить количество ароматических групп в молекуле $\left(R_{G}\right)$ и количество бензольных ядер в группе $\left(R_{a r}\right)$ по простым зависимостям $\left[{ }^{17}\right]$ :

$$
\begin{aligned}
R_{G} & =\frac{C_{a r}}{7\left(\frac{C_{a r}}{C_{a r}^{s, u}}\right)^{2}-1} \\
R_{a r} & =\frac{C_{a r}-C_{a r}^{s, u}}{2}+1,
\end{aligned}
$$

где $C_{a r}$ и $C_{a r}^{s, u}$ - соответственно общее количество атомов углерода в аро-

* В некоторых случаях для повышения растворимости добавлялся $\mathrm{CHCl}_{\mathbf{s}}$. 
матических структурах и количество замещаемых атомов углерода в тех же структурах.

По ЯМР-спектрам углерода в общем случае невозможно различить углеродные атомы в ароматических кольцах и в двойных связях, а определение последних по ИК-спектрам в сложных смесях связано с некоторыми трудностями. Однако расчет ряда гетероатомных структур, содержащих двойные связи (в том числе бензофурановые и пироновые кольца), показал приблизительную применимость этих зависимостей также в данном случае (учет гетероатомов см. ниже).

Обработка опытных данных проводилась на ЭВМ «Наири-С» по выведенным нами формулам

$$
\begin{aligned}
H_{i} & =a_{i} \cdot \mathrm{H} \% \cdot M / 100, \\
C_{i} & =A_{i} \cdot \mathrm{C} \% \cdot M / 1200, \\
\mathrm{H}_{12}^{\prime} & =\mathrm{H}_{1}+\mathrm{H}_{2}+2(\mathrm{O}-\mathrm{OH}), \\
\mathrm{C}_{1}^{\prime} & =\mathrm{C}_{1}+(\mathrm{O}-\mathrm{OH}), \\
\mathrm{C}_{2}^{\prime} & =\mathrm{C}_{2}-\mathrm{CO}, \\
R_{G} & =\frac{\mathrm{C}_{2}^{\prime}}{7\left(\frac{\mathrm{C}_{2}^{\prime} \cdot \mathrm{H}_{12}^{\prime}}{\mathrm{H}_{3} \cdot \mathrm{H}_{12}^{\prime}+\mathrm{C}_{1}^{\prime} \mathrm{H}_{2}}\right)^{2}-1}, \\
R_{a r}= & \frac{\mathrm{C}_{2}^{\prime} \cdot \mathrm{H}_{12}^{\prime}-\mathrm{H}_{3} \mathrm{H}_{12}^{\prime}-\mathrm{C}_{1}^{\prime} \mathrm{H}_{2}}{2 \mathrm{H}_{12}^{\prime}}+1,
\end{aligned}
$$

где (в скобках показаны ошибки соответствующих величин)

С $\%( \pm 0,3), \mathrm{H} \%( \pm 0,2)$, O \% $( \pm 0,5)$ - процентное содержание указанных элементов;

$M( \pm 10)$ - молекулярный вес;

$a_{1}( \pm 0,04)$ - доля поверхности сигналов в области $0,5-1,8$ м. д. по $\delta$-шкале, обусловленных протонами в метиленовых и метильных группах;

$a_{2}( \pm 0,02)-$ доля поверхности сигналов в области $1,8-3,5$ м. д., протоны в указанных группах соединены к углероду в $s p^{2}$ состоянии;

$a_{3}( \pm 0,02)$ - доля поверхности сигналов в области $5,5-8,0$ м. д., протоны в ароматических структурах, в двойных связях и в гидроксильных группах (в этерифицированных пробах протоны гидроксильных групп измерялись отдельно по сигналу около 0,25 м. д.);

$A_{1}( \pm 0,02)$ - доля поверхности сигналов в области $145-195$ м. д. $\left(\sigma_{C S_{2}}=0\right)$, насыщенные атомы углерода;

$A_{2}( \pm 0,02)$ - доля поверхности сигналов в области $35-100$ м. д., углерод в ароматических и ненасыщенных структурах;

$\mathrm{OH}( \pm 0,1)$ и $\mathrm{CO}( \pm 0,1)$ - соответственно количество гидроксильных групп (по Михкельсону) и карбонильных групп (по ИК-спектру) в молекуле;

$\mathrm{H}_{1}( \pm 2), \mathrm{H}_{2}( \pm 1), \mathrm{H}_{3}( \pm 1), \mathrm{C}_{1}( \pm 0,8), \mathrm{C}_{2}( \pm 0,8), \mathrm{O}( \pm 0,2)$ - количество соответствующих атомов водорода, углерода и кислорода;

$\mathrm{H}_{12}^{\prime} / \mathrm{H}_{2}( \pm 1)$ - число углеродных атомов на средний насыщенный заместитель.

Ошибки значений $a_{1}$ и $A_{1}$ представляют собой средние абсолютные ошибки, полученные при измерении спектров ${ }^{1} \mathrm{H}$ пяти алкилрезорцинов 
(или их эфиров) и спектров ${ }^{13} \mathrm{C} 17$ алкилрезорцинов. Ошибки остальных величин являются максимальными ошибками соответствующих анализов. На основе ошибок исходных данных $(\Delta x)$ были найдены ошибки расчетных величин $(\Delta y)$ при помощи известной зависимости

$$
\Delta y=\left(\frac{\partial f}{\partial x_{1}}\right) \Delta x_{1}+\left(\frac{\partial f}{\partial x_{2}}\right) \Delta x_{2}+\ldots
$$

Значения $\Delta R_{G}= \pm 0,7$ и $\Delta R_{a r}= \pm 1,0$ весьма большие (последнюю величину даже нет смысла высчитывать). Рассмотрение составляющих $\Delta R_{G}$ для одной пробы (табл. 2) показало, что основная ошибка связана с измерением ЯМР-спектров. Если $\Delta R_{G}= \pm 0,2$, то $\Delta a_{i}=\Delta A_{i}=0,01$ и

Таблица 2

Составляющие значения $\Delta R_{G}$ для пробы I

\begin{tabular}{c|c|c||c|c|c}
\hline$x$ & $\frac{\partial y}{\partial x} \cdot 10^{3}$ & $\frac{\partial y}{\partial x} \Delta x$ & $x$ & $\frac{\partial y}{\partial x} \cdot 10^{3}$ & $\frac{\partial y}{\partial x} \Delta x$ \\
\hline $\mathrm{C} \%$ & 8,29 & 0,002 & $a_{1}$ & 1530 & 0,061 \\
$\mathrm{H} \%$ & 243,4 & 0,048 & $a_{2}$ & 3256 & 0,065 \\
$\mathrm{O} \%$ & 1,13 & 0,001 & $a_{3}$ & 10058 & 0,201 \\
$\mathrm{M}$ & 3,94 & 0,039 & $A_{1}$ & 2448 & 0,049 \\
$\mathrm{OH}$ & 4,91 & 0,000 & $A_{2}$ & 3748 & 0,075 \\
$\mathrm{CO}$ & 155,9 & 0,016 & & Cумма & 0,451 \\
& Сумма & 0,106 & & $\Delta R_{G}$ & 0,559
\end{tabular}

$\Delta H_{i}=0,2$ (при пренебрежении ошибками других исходных данных), в таком случае $\Delta R_{a r}= \pm 0,4$. Поэтому при использовании зависимости (2) требуется очень высокая точность определения величины $C_{a r}^{s, u}$.

Отметим, что определение значений $a_{1}$ и $a_{2}$ в этерифицированных пробах точнее по сравнению с определением в пробах со свободными гидроксильными группами.

Точность определения количества метиловых групп в ИК-спектрах по формуле $n=\left(\varepsilon_{2930}+100\right) / 75$ составляла для фенолов с неразветвленными цепями \pm 1 , для более сложных смесей $\pm 2\left[{ }^{14,18}\right]$.

Спектральные методы позволяют в сложных смесях определить лишь самые характерные структурные элементы. Это обусловлено появлением фона и в случае спектров ${ }^{1} \mathrm{H}$ расширением полос вследствие повышения вязкости в более концентрированных растворах.

\section{Результаты и их обсуждение}

Основное 'количество протонов принадлежит насыщенным атомам углерода (табл. 3). Эти протоны находятся главным образом в метиленовых и метильных группах неразветвленных алифатических цепей (соответственно 1,28 и 0,90 м. д.), а также в этих же группах, связанных с углеродом в $s p^{2}$ состоянии (ароматические ядра, ненасыщенные связи, карбонильные группы и др.). Сигналов, характерных для протонов разветвленных алифатических цепей $(1,43-1,65$ м. д.), пяти- или шестичленных нафтеновых колец (1,3-1,5 м. д.) в протонных спектрах различить не удалось. Указанные элементы несомненно в смоле присутствуют (6), но их количество небольшое. Также нет сигналов протонов группы $-\mathrm{O}-\mathrm{CH}_{2}-$. 
Распределение атомов водорода и углерода в исследуемых пробах и результаты статистического расчета

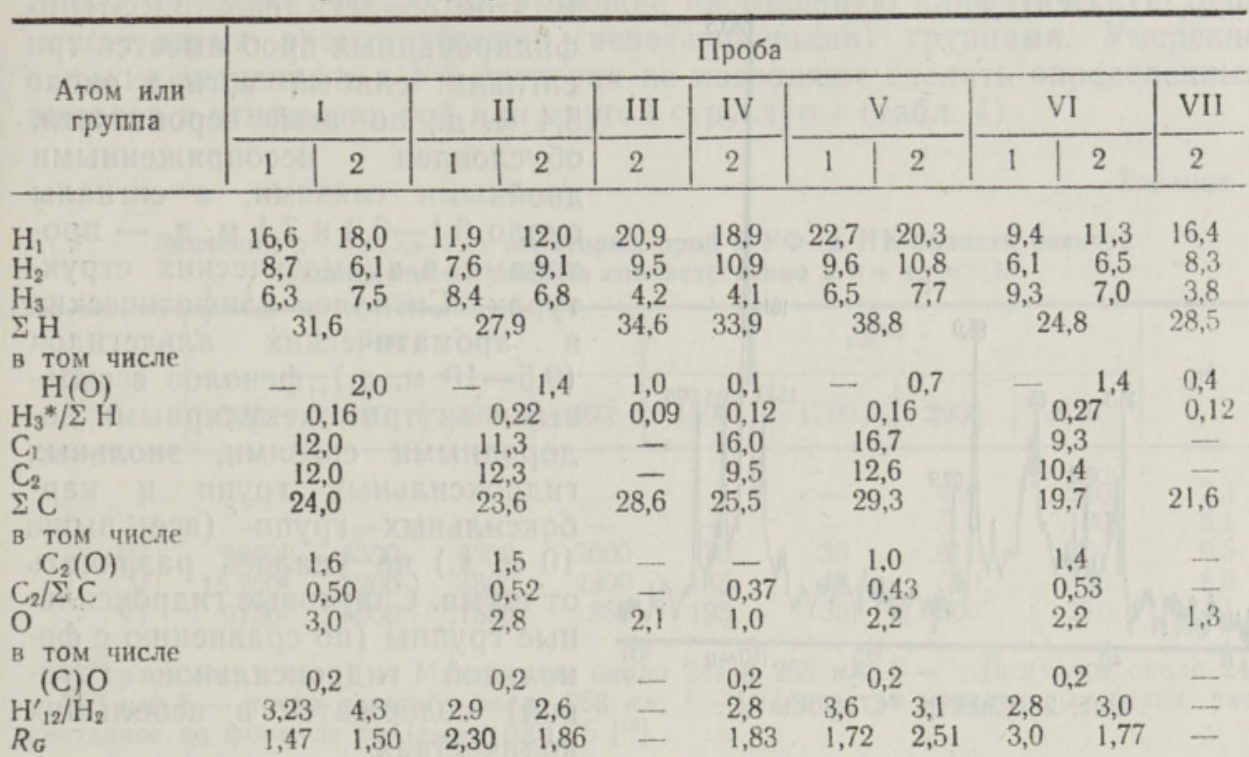

Примечание. $1-$ в $\mathrm{CCl}_{4}\left(+\mathrm{CHCl}_{3}\right) ; 2-\mathrm{B}_{4}$ после этерифицирования.

* За вычетом количества Н(O) по Михкельсону.

По ${ }^{13}$ С-спектрам (рис. 1, 2) количество насыщенных атомов углерода в остатке атмосферной дистилляции смолы (рассчитанное по спектрам проб IV, V, VI) составляет не менее $60 \%$ и примерно $45-50 \%$ в фенолах (пробы I, II, VI). Общие для всех проб сигналы около 161-162, 164, $170-171$ и $179-180$ м. д. характерны для неразветвленных алифатических цепей. Сигнал около 157 м. д., характерный для $\alpha-\mathrm{CH}_{2}$ группы цепи, стоящей у ароматического ядра в мета-положении относительно гидроксильных групп, виден в спектрах всех проб (кроме углеводородов). В спектре пробы II имеется сигнал 185 м. д. $\left(2-\mathrm{CH}_{3}\right.$ группа в 2 -алкилрезорцинах). В спектрах нет сигналов, характерных для разветвленных цепей $(165,172,182$ м. д.). Отметим, что в спектрах проб IV, V, VI фон растянут значительно ниже 145 м. д.

По ИК-спектрам количество метиленовых групп в средней молекуле 7-10 (в пробе VI естественно ниже, см. табл. 4). Это намного меньше общего количества насыщенных углеродных атомов и піоэтому в тяжелой части смолы лишь $50-60 \%$ из них находится

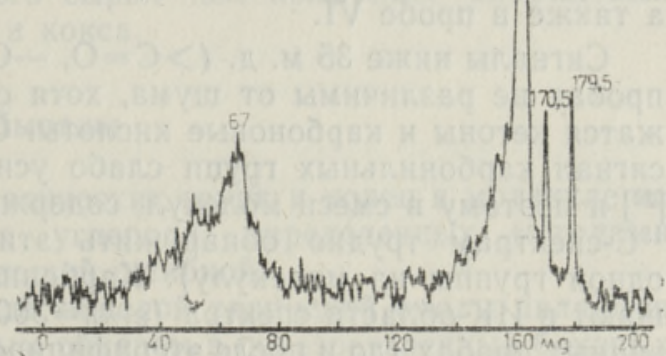

Рис. 1. Спектр ${ }^{13} \mathrm{C}$ пробы V. в длинных боковых цепях.

C этим согласуется относительно высокая доля протонов группы $\mathrm{H}_{2}$. 
Во всех пробах доля протонов, находящихся в ароматических структурах (или у двойных связей) (5,4-7,5 м. д.), составляет лишь $10-20 \%$ (только в пробе VI около $30 \%$ ).

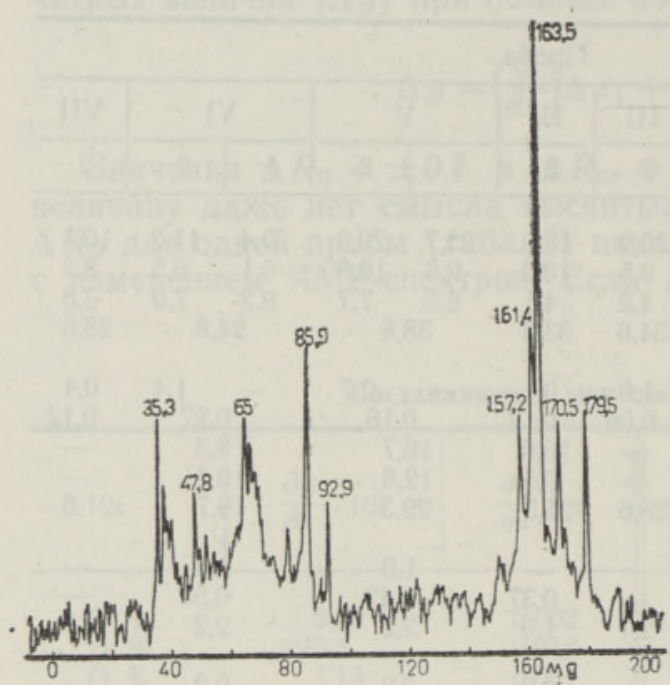

Рис. 2. Спектр ${ }^{13} \mathrm{C}$ пробы VI. В этой области спектра этерифицированных проб имеется три сигнала: слабый сигнал около 5,4 м. д., по всей вероятности, обусловлен несопряженными двойными связями, а сигналы около $6,1-6,3$ и 7,1 м. д. - протонами в ароматических структурах. Сигналов алифатических и ароматических альдегидов (9,5-10 м. д.), фенолов с сильными внутримолекулярными водородными связями, энольных гидроксильных групп и карбоксильных групп (все выше 10 м. д.) не удалось различить от шума. Спиртовые гидроксильные группы (по сравнению с фенольной гидроксильной группой) содержатся в небольших количествах.

Область спектра ${ }^{13} \mathrm{C} 35-100$ м. д., характерная для углерода в $\mathrm{C}_{s p}{ }^{2}$ состоянии, подтверждает вывод о важной роли структурного элемента $1,3-(\mathrm{OH})_{2}-5-\left(\mathrm{CH}_{2}\right)_{n}-\mathrm{C}_{6} \mathrm{H}_{3}$ в двухатомных фенолах [19]. Об этом свидетельствуют 4 характерные линии с чередующимися интенсивностями около 36 (1,3-С), 47-48 (5-C), 85-86 (4,6-С) и 92-93 м. д. (2-C). Слабые сигналы при $37-40$ м. д. могут быть обусловлены $\mathrm{C}-(\mathrm{O}-)$ атомами других алкилрезорцинов, определенных диоксинафталинов, гетероциклических соединений. Сигналы C $(-\mathrm{OH})$ атомов пирокатехина (43,2 м.д.), 4,4-диоксидифенила $(59,4$ м.д.) и других многоатомных фенолов (кроме флороглюцина, поглощающего при 35,4 м. д.) слабые либо отсутствуют вообще. В одноатомных фенолах можно предположить значительное количество 2-алкилрезорцинов. Это объясняется низкой эффективностью препаративного разделения на тонком слое окиси алюминия. В пробе V сигналы около 36 и 37,1 м. д. имеют примерно равную интенсивность, а в углеводородах (проба IV) не различимы от шума. Группа сигналов около 66 м. д., характерная для ароматических, а также ненасыщенных углеводородов, особенно интенсивна в пробе IV, а также в пробе VI.

Сигналы ниже 35 м. д. ( $>\mathrm{C}=\mathrm{O},-\mathrm{CHO},-\mathrm{COO}-,-\mathrm{COOH})$ во всех пробах не различимы от шума, хотя общеизвестно, что в смоле содержатся кетоны и карбоновые кислоты. Однако следует иметь в виду, что сигнал карбонильных групп слабо усиливается эффектом Оверхаузера [20] и поэтому в смеси молекул, содержащих 20-30 атомов углерода, по ${ }^{13} \mathrm{C}$-спектрам трудно обнаружить эти группы (даже при содержании одной группы на молекулу). Карбонильные группы интенсивно поглощают в ИК-области спектра $\left(\varepsilon_{17 n n}=300-500 \Omega /\right.$ моль.$\left.с м\right)$ [21]. В исследованных пробах (до и после этерифицирования) коэффициент поглошения около $1670-1750 \mathrm{~cm}^{-1}$ не превышал 20-50 $/$ /моль му содержание $\mathrm{C}=\mathrm{O}$ групп не может быть выше $0,2-0,3$ групп на молекулу (с учетом более низкого значения $\varepsilon$ в спектрах синтезированных нами пиронов). 
Все значения $R_{G}$ выше единицы и поэтому можно предположить, несмот, н на значительную погрешность этой величины, что в тяжелой сланцевой смоле содержатся наряду с конденсированными ароматическими кольцами также структуры, имеющие насыщенную алифатическую цепь между двумя ароматическими (ненасыщенными) группами. Умеренно высокие значения $\varepsilon$ в УФ-спектрах не позволяют сделать определенных выводов в отношении той или другой структуры (табл. 4).

Таблища 4

Значения $\varepsilon(л /$ моль. см) некоторых проб в УФ- и ИК-области спектра (длина волны указана соответственно в $\mathrm{HM}_{\text {и }} \mathrm{CM}^{-1}$ )

\begin{tabular}{|c|c|c|c|c|c|c|c|c|c|}
\hline \multirow{2}{*}{ Проба } & \multicolumn{4}{|c|}{$H M$} & \multicolumn{4}{|c|}{$C M^{-1}$} & \multirow{2}{*}{$n^{4}$} \\
\hline & 240 & 280 & 320 & 360 & 1600 & 1700 & 2930 & 3610 & \\
\hline $\begin{array}{l}\text { I } \\
\text { II } \\
\text { IV } \\
\text { V } \\
\text { VI }\end{array}$ & $\begin{array}{c}\overline{-} \\
9800^{1} \\
15200^{2} \\
9750^{3}\end{array}$ & $\begin{array}{l}\overline{-} \\
6300 \\
8200 \\
5000\end{array}$ & $\begin{array}{l}\overline{-} \\
4300 \\
4800 \\
1800\end{array}$ & $\begin{array}{r}\overline{-} \\
2000 \\
2300 \\
850\end{array}$ & $\begin{array}{r}\overline{7} \\
70 \\
145 \\
195\end{array}$ & $\begin{array}{l}\overline{-} \\
30 \\
40 \\
30\end{array}$ & $\begin{array}{l}450 \\
510 \\
615 \\
570 \\
300\end{array}$ & $\begin{array}{r}240 \\
180 \\
50 \\
120 \\
210\end{array}$ & $\begin{array}{l}7,3 \\
8,1 \\
9,5 \\
8,9 \\
4,1\end{array}$ \\
\hline
\end{tabular}

П рим е чание. 1 - Максимумы около 247 и 255 нм, ${ }^{2}$ - максимумы около 245 и $260 \mathrm{mм}^{3}$ - точка перегиба около $258 \mathrm{\mu м},{ }^{4}$ - количество метиленовых групп, рассчитанное по формуле $n=\left(\varepsilon_{2930}+100\right) / 75\left[{ }^{18}\right]$.

Доля насыщенного углерода в тяжелой смоле больше, чем предполагалось до сих пор. Кроме того, этот насыщенный углерод находится главным образом в неразветвленных алифатических цепях. Кажется, что определение распределения углерода химическими методами дает неправильное представление вследствие принятых при истолковании результатов деструкции дополнительных допущений, либо из-за процесса циклизации, протекающей в ходе химической обработки. Примером легкости циклизации может быть образование алкилрезорцинов путем альдольной конденсации $\beta$-трикетонов при комнатной температуре $\left[{ }^{22}\right]$. Нет сомнений, что совместное применение методов молекулярной дистилляции, жидкофазного хроматографирования и спектрального анализа позволит выяснить этот вопрос более подробно.

Полученные данные дают определенное представление о средней молекуле тяжелой смолы и составляющих ее групп соединений. Различение алифатической насыщенной и ароматической частей средней молекулы и дополнительные данные о структуре этих элементов позволяют оценить потенциальные возможности этого сырья для получения олефиновых углеводородов, алкилрезорцинов и кокса.

\section{Выводы}

1. Показано, что расчет ароматических групп и колец в молекуле по количеству замещаемых атомов углерода, определенных методами ЯМР-спектроскопии, связан с большой ошибкой.

2. Около $60 \%$ атомов углерода тяжелой сланцевой смолы являются насыщенными и находятся главным образом в неразветвленных боковых цепях.

3. В средней молекуле тяжелой смолы содержится преимущественно две ароматические (ненасыщенных) группы, соединенные между собой насыщенной цепью. 
4. Подтверждены данные о содержании в тяжелой смоле бензольных колец, содержащих две гидроксильные группы и алкильную цепь, симметричных относительно друг друга.

\section{ЛИТЕРАТУРА}

1. А а рна А. Я., Уров К. Э., Тр. Таллинск. политехн. ин-та, Серня А, № 228. 27 (1965).

2. Каск К. А., Михкельсон В. А., Тр. Таллинск, политехн. ин-та, Серия А, № 97, 68 (1957).

3. Ш ульман А. И., Исследование процесса битуминизации обогащенного сланца. Автореф. дисс. канд. техн. н., Л., 1968.

4. Эд ельштейн Н. Г., Тр. Ин-та горюч. ископ., 3, 109 (1954).

5. Кокурин А. К., Галуткина К. А., Сланцевая смола и ее использование. Обзор ЦНИиТәНефтехим'а, М., 1967.

6. Э й з ен О. Г., Методы анализа смол переработки твердого топлива и химический состав эстонской сланцевой смолы. Дисс. док. хим. н., Таллин, 1967.

7. Л е э пер Р. Я., И оон ас Р. Э., С ер еб рянни ков Н. Д., Тр. Ин-та сланцев, вып. 15,227 (1966).

8. Михкельсон В. Я., Тр. Таллинск. политехн, ин-та, Серия А, № 210, 267 (1964).

9. Михкельсон В. Я., В сб.: Методы анализа горючих сланцев и продуктов их переработки, Таллин, 1961.

10. С юг и с А., Л и пп м а а Э., Изв. АН ЭССР, Физ. Матем., 16, 81 (1967).

11. Dietrich M. W., N a sh J. S., Keller R. E., Anal. Chem., 38, 1479 (1966).

12. B r u n e H. A., Tetrahedron, 24, 79 (1968).

13. Пехк Т., Лилле Ю., Липпма ЭЭ., Биттер Л., Изв. АН ЭССР, Хим. Геол.. $19,283(1970)$.

14. Лилле Ю. Э., Пей н а У. Л., Биттер Л. А., Тр. Таллинск. политехн. ин-та, Серия А, № 311, 102 (1971).

15. High Resolution NMR Spectra Catalog, Vol, 1, II, Varian Associates 1962, 1963.

16. Эм сли Дж., Фин ей Дж., Са ткли ф Л., Спектроскопия ЯМР высокого разрешения, I, II. М., 1968, 1969.

17. Kn ight S. A., Chem. and Ind., 1967, 1920.

18. Егоров Ю. П., Л у 6 у ж Е. Д., Докл. АН СССР, 136, 342 (1961).

19. Лилле Ю., Биттер Л., Мурд А., Пейнар У., Кундель Х., Тр. Таллинск. политехн, ин-та, Серия А, № 311, 127 (1971).

20. Allerhand A., Cochran D. W., Doddreli D., Proc. Nat. Acad. Sci. USA, 67, $1093(1970)$.

21. Бранд Дж., Эглинтон Г., Применение спектроскопии в органической химии, M., 1967, c. 128.

22. Harris T. M., Carney R. L., J. Am. Chem. Soc., 89, 6734 (1967).

\section{НИИС Институт сланцев}

Институт кибернетики

Академии наук Эстонской ССР

\section{Поступила в редакцию} $13 / \mathrm{X} 1971$

\section{O. LILLE, T. PEHK, T. PURRE, L. BITTER}

\section{POLEVKIVI RASKEOLI STRUKTUURI UURIMINE TUUMA MAGNETRESONANTSSPEKTROSKOOPIA ABIL}

Pōlevkivi raskeōli lahutati süsivesinikeks, neutraalseiks hapnikuühendeiks ja fenoolideks ning uuriti neid spektraalseil meetodeil $\left({ }^{1} \mathrm{H}\right.$ - ja ${ }^{13} \mathrm{C}$-tuumade magnetresonants, IP- ja UV-spektroskoopia). Selgus, et $60 \%$ raskeôli süsiniku aatomeist asub küllastatud sirgeis süsivesinikahelais. Kaks hüdroksüülrühma ja alküülahel asuvad benseeni tuumąs sümmeetriliselt. Keskmises molekulis on eelistatult kaks aromaatset gruppi. 
O. LILLE, T. PEHK, T. PURRE, L. BITTER

\section{EXAMINATION OF THE STRUCTURE OF HEAVY SHALE OIL BY MEANS OF NMR-SPECTROSCOPY}

Heavy shale oil was separated into hydrocarbons, neutral oxygen compounds and phenols by treatment with organic solvents. Each group was examined by means of NMR, IR and UV-spectroscopy. It was proved that on the average 60 per cent of carbon atoms of heavy shale oil are located in unbranched saturated hydrocarbon chains. Two hydroxylic groups and an alkyl chain are located symmetrically by the benzene nucleus. The intermediate molecule contains mostly two aromatic groups. 